\title{
Broadband Microstrip Patch Antenna using Slot
}

\author{
Sharad Mishra \\ M.Tech Student, Department of ECE, \\ NRI Institute of Research and Technology, Bhopal,
}

\author{
Omesh Singh Hada \\ Assistant Professor, Department of ECE, \\ NRI Institute of Research and Technology, Bhopal,
}

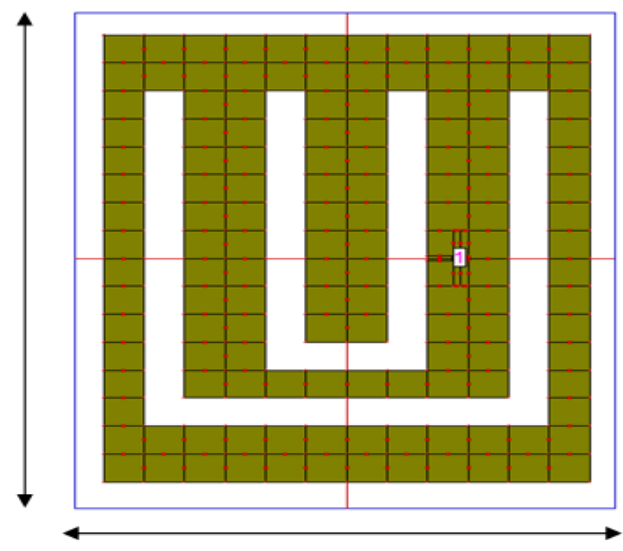

Fig.1. Structure of proposed antenna

The electric field lines in the antenna mostly move in the substrate and even a bit out of the substrate in to the air so the value of $\varepsilon_{\text {reff }}$ is slightly less than that of $\varepsilon_{\mathrm{r}}$ [12]. The effective dielectric constant is given as

$$
\varepsilon_{\text {reff }}=\frac{\varepsilon_{\mathrm{r}}+1}{2}+\frac{\varepsilon_{\mathrm{r}}-1}{2}\left[1+12 \frac{h}{w}\right]^{-1 / 2}
$$

The change in length is calculated as:

$$
\Delta \mathrm{L}=0.412 \mathrm{~h} \frac{\left(\varepsilon_{\text {reff }}+0.30\right)\left(\frac{\mathrm{w}}{\mathrm{h}}+0.264\right)}{\left(\varepsilon_{\text {reff }}-0.258\right)\left(\frac{\mathrm{w}}{\mathrm{h}}+0.8\right)}
$$

The width of proposed antenna can be calculated by using effective dielectric constant and wave length $=\mathrm{C} / \mathrm{f}_{0}$ as

$$
\mathrm{W}=\frac{C}{2 f o \sqrt{\frac{\varepsilon_{\text {reff }}+1}{2}}}
$$

The effective length $\left(L_{e f f}\right)$ and actual length (L) of proposed antenna is calculated as

$$
L_{e f f}=\frac{C}{2 f o \sqrt{\varepsilon_{\text {reff }}}} \& L=L_{e f f}-2 \Delta L
$$

\subsection{Antenna Geometry}

The proposed antenna geometry is shown in fig. 2,where a coaxial feed rectangular patch is printed over [1] Glass epoxy FR4 substrate of thickness $h=1.5 \mathrm{~mm}$, permittivity $\varepsilon_{\mathrm{r}}=4.3$, and tangent loss is 0.019 . Two U-slots are cut on the patch's surface separated by GND plane $\mathrm{L}_{\mathrm{g}} \times \mathrm{W}_{\mathrm{g}}=26.6 \times 32 \mathrm{~mm}$. The GND plane and patch is separated by substrate. The size of proposed antenna is calculated by using formulas described above. The dimensions of Antenna that give a broadband impedance bandwidth are shown in fig. 2 . 

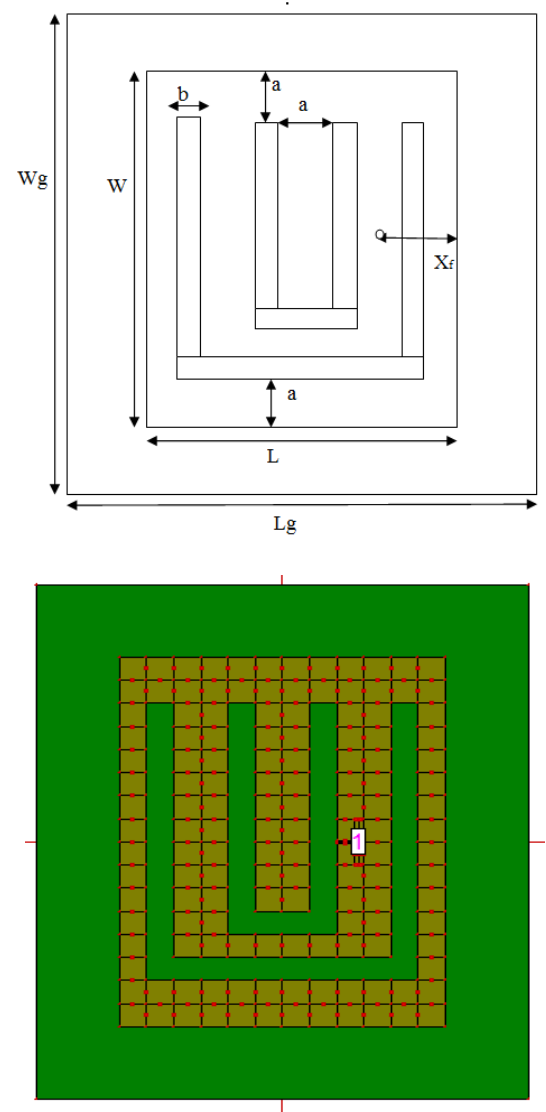

Fig.2. Geometry of proposed antenna (Top view)

Table 1: Dimensions of proposed microstrip patch antenna

\begin{tabular}{|l|c|c|c|c|c|c|c|}
\hline Parameter & $\mathbf{L}_{\mathbf{g}}$ & $\mathbf{W}_{\mathbf{g}}$ & $\mathbf{L}$ & $\mathbf{W}$ & $\mathbf{a}$ & $\mathbf{b}$ & $\mathbf{X}_{\mathbf{f}}$ \\
\hline Unit $(\mathrm{mm})$ & 26.6 & 32 & 17.6 & 23 & 3 & 1.5 & 4.8 \\
\hline
\end{tabular}

\subsection{Parametric Study}

The parameters which are responsible for antenna performance are chosen for parametric study. These parameters are length of patch (L), width of patch (W), dielectric constant $\left(\varepsilon_{\mathrm{r}}\right)$ and slot size. Patch length and slot length are responsible for electric length, whereas $\mathrm{W}$ changes patch impedance. Slot size and location shows current distribution on patch's surface [1]. To study the antenna performance parametric study is carried out using IE3D simulation software. The simulation results shows that by changing the parameter of microstrip patch antenna the performance of antenna can be improve. After simulation impedance bandwidth $>37 \%$ and return loss -38.82 is achieved at $5.36 \mathrm{GHz}$.

\section{SIMULATION RESULTS AND DISCUSSION}

The results of proposed antenna designed on FR4 substrates using coaxial feed technique, simulated and measured by using IE3D simulator are shown in Fig 3.From the figure it is shown that broadening the antenna bandwidth because of using slots on patch's surface. According to the simulated results, slot technique increases impedance bandwidth of antenna. The bandwidth of proposed antenna is $37 \%(4.4 \mathrm{GHz}$ $-6.4 \mathrm{GHz}$ ) is achieved. The return loss is $-38.82 \mathrm{~dB}$ at 5.36 $\mathrm{GHz}$ and -37.18 at $4.75 \mathrm{GHz}$ achieved. Return loss represents the amount of power which is reflected back to source and should be as small as possible. Fig. 3 shows the simulated $S_{11}$ plot of proposed antenna. The bandwidth of antenna is calculated at $-10 \mathrm{~dB}$ of $\mathrm{S}_{11}$ plot which represents the usable frequency with reasonable performance.

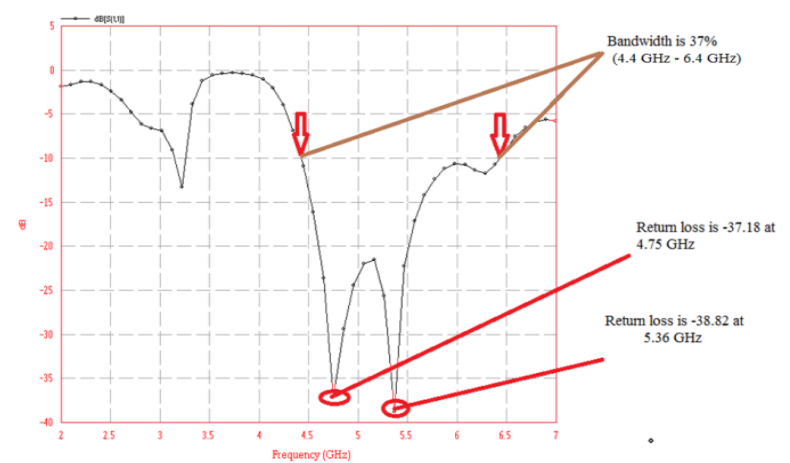

Fig.3. Simulated return loss of proposed antenna.

The simulated result of proposed antenna shows that the VSWR (fig.4) is minimum (1.023) and directivity which is the maximum directional gain of antenna is $4.2 \mathrm{dBi}$ at $5.36 \mathrm{GHz}$ frequency (fig.5). The Smith chart (Fig.6) shows the normalized impedance of proposed antenna. Fig.10 shows the magnitude of Z-parameter which is about $50 \mathrm{ohm}$ at $5.36 \mathrm{GHz}$ frequency. The antenna and radiation efficiency $80 \%$ achieved after simulation of proposed antenna is shown in Fig.7. The measured radiation pattern E-total is shown in fig. 8 and polar plot of E-total is shown in fig.9. Polarization of radiation represents the property of electromagnetic wave describing the electric field vector as the time varying direction.

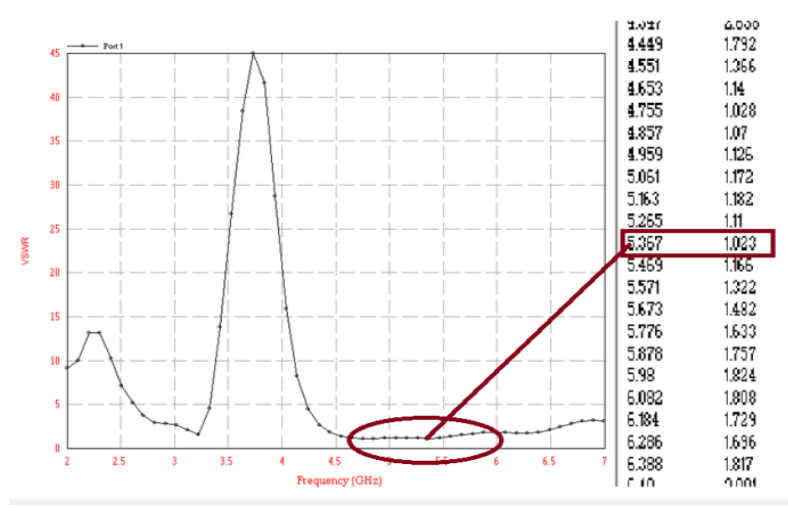

Fig.4. VSWR of proposed antenna

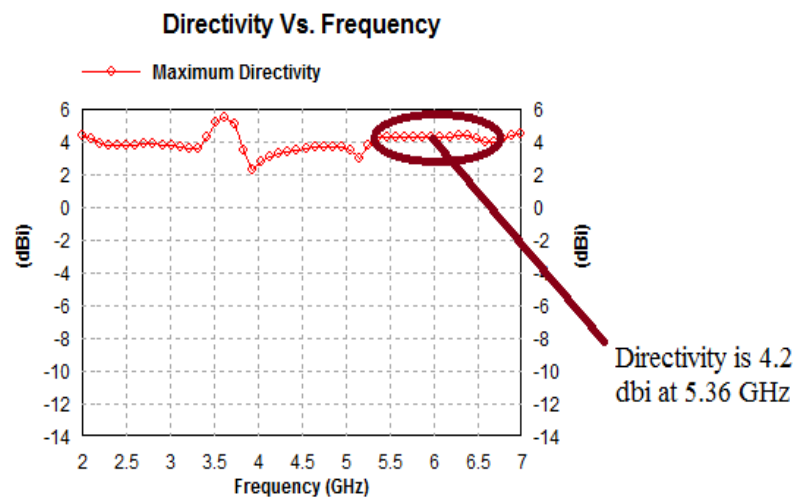

Fig.5. Directivity of proposed antenna. 


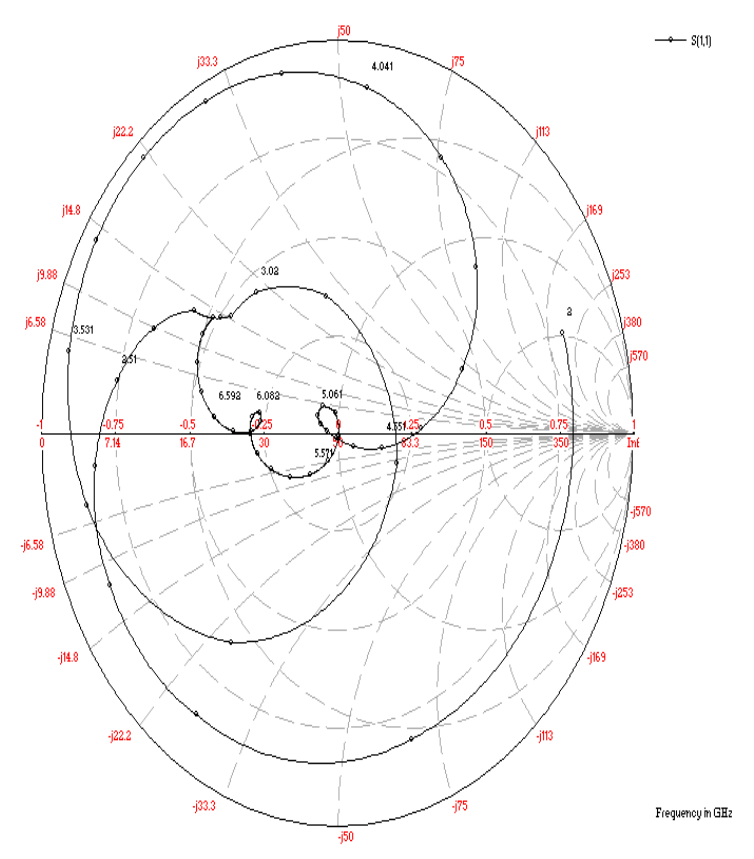

Fig.6. Smith chart of proposed antenna.

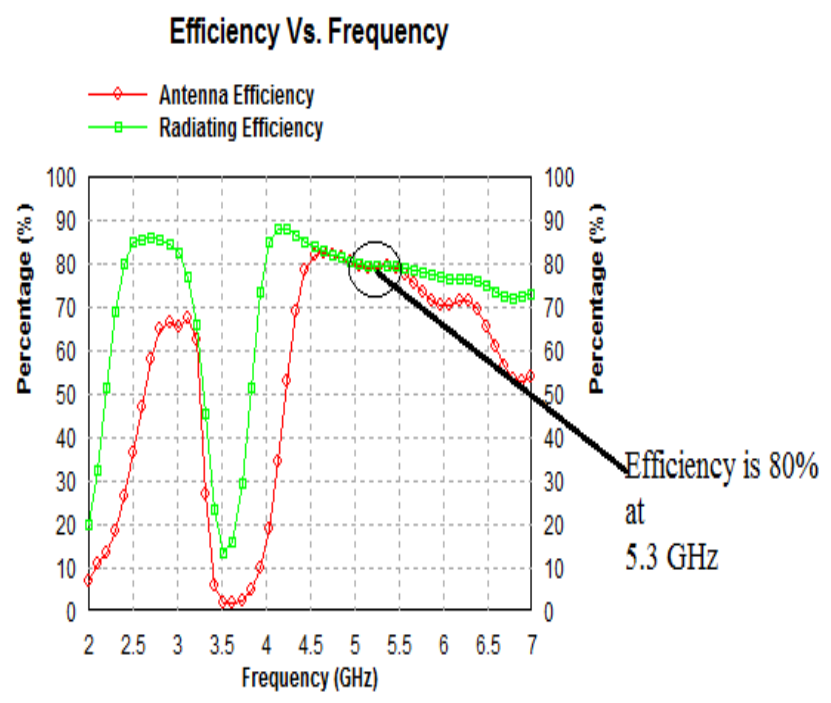

Fig.7. Antenna and radiation efficiency of propose antenna.

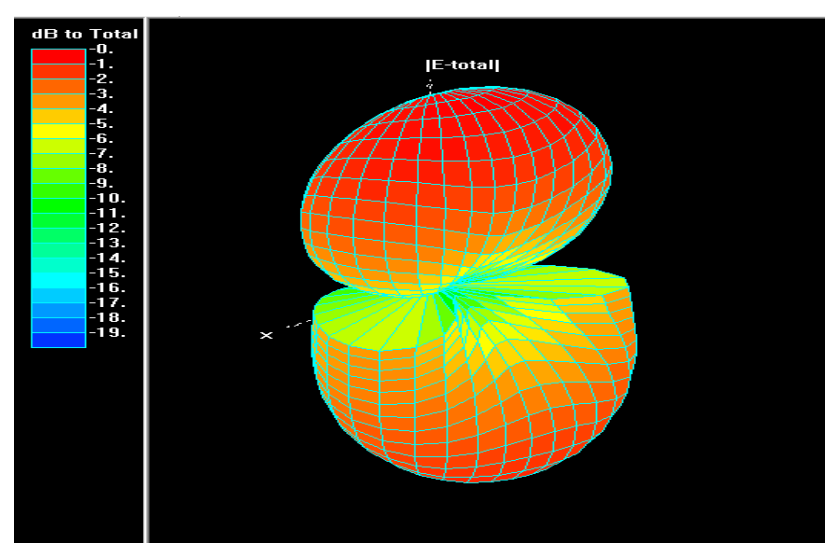

Fig.8. E-total of proposed antenna

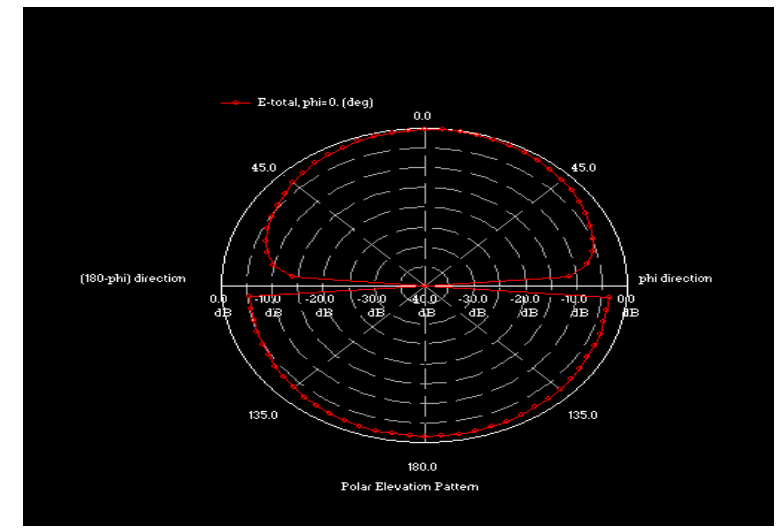

Fig.9. Polar plot of E-total of proposed antenna

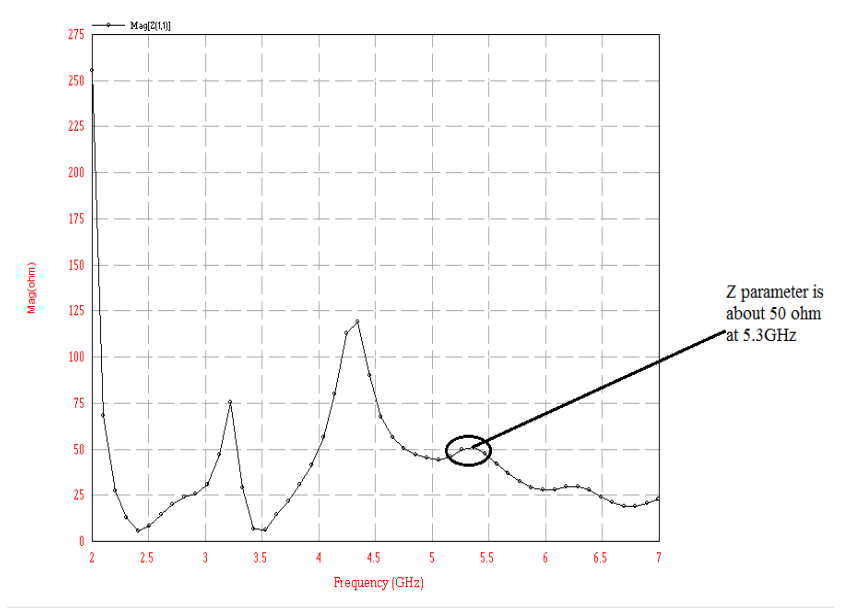

Fig.10. Magnitude of Z-parameter of proposed antenna

\section{CONCLUSION}

Broadband microstrip patch antenna using dual U-slot with low profile has been proposed and analysis of results has been done by using IE3D simulator. The results of proposed antenna shows that by using proper slot size on patch's surface the performance of antenna can be improve. The proposed antenna has $37 \%$ impedance bandwidth $(4.4 \mathrm{GHz}-$ $6.4 \mathrm{GHz}$ ) achieved in C-band. The return loss $-38.82 \mathrm{~dB}$ and VSWR 1.023 achieved at $5.36 \mathrm{GHz}$. The proposed antenna efficiency $80 \%$ and directivity 4.2 is measured as the result of simulation at $5.36 \mathrm{GHz}$. The proposed antenna is desirable candidate for satellite communication and wireless telephone network.

\section{REFERENCES}

[1] Ahmed Khidre, Kai-Fong Lee, Atef Z. Elsherbeni, and Fan Yang, "Wide Band Dual Beam U-Slot Microstrip Antenna", IEEE Transactions on Antenna and Propagation, vol. 61, no. 3,pp.1415-1418, March 2013.

[2] Kaushik Mandal and Partha Prtim Sarkar" High Gain Wide-Band U-Shaped Patch Antennas With Modified Ground Planes", IEEE Transactions on Antenna and Propagation, vol. 61, no.4,pp.2279-2282,April 2013.

[3] Teruhisa Nakamura and Takeshi Fukusako, "Broadband Design of Circularly Polarized Microstrip Patch Antenna Using Artificial Ground Structure With Rectangular Unit Cells" IEEE Transactions on Antenna and Propagation, VOL. 59, NO.6, June 2011. 
[4] Juhua Liu and Quan Xue, 'Broadband Long Rectangular Patch Antenna WithHigh Gain and Vertical Polarization", IEEE Transactions on Antenna and Propagation, vol.61, no.2, pp.539-546, February 2013.

[5] Mingjian Li and Kwai-Man Luk," A Low-Profile Wideband Planar Antenna", IEEE Transactions on Antenna and Propagation, VOL. 61, NO. 9, pp.44114418, September 2013.

[6] Ahmed Khidre, Kai-Fong Lee, Fan Yang, and Atef Z. Elsherbeni "Circular Polarization Reconfigurable Wideband E-Shaped Patch Antenna for Wireless Applications",IEEE Transactions on Antenna and Propagation , vol. 61, no.2,pp.960-965, February 2013.

[7] Wenwen Yang and Jianyi Zhou,"Wideband Low-Profile Substrate Integrated Waveguide Cavity-Backed EShaped Patch Antenna", IEEE Transactions on Antenna and Propagation, vol.12,2013.
[8] S. Bhunia," Effects of Slot Loading on Microstrip Patch Antennas", International Journal of Wired and Wireless Communications Vol.1, Issue 1, October, 2012.

[9] Purvai Rastogi and Kanchan Cecil," S and C Bands Multilayer T-Slot Photonic Band gap Micro Strip Antenna”, IOSR Journal of Engineering, Vol. 2(4) pp: 773-776,April 2012.

[10] S. T. Fan, Y. Z. Yin, B. Lee, "Bandwidth Enhancement of a Printed Slot Antenna with a Pair of Parasitic Patches IEEE Transactions on Antenna and Wireless Propagation Letters, VOL. 11, 2012.

[11] D. M.Pozar, Microwave Engineering. New York: Addison-Wesley, 1990, p. 185.

[12] C. A. Balanis, Antenna Theory: Analysis and Design. New York: Wiley, 1997, p. 734 